University of Nebraska - Lincoln

DigitalCommons@University of Nebraska - Lincoln

Publications, Agencies and Staff of the U.S.

Department of Commerce

U.S. Department of Commerce

2009

\title{
Contrasting patterns of genetic diversity at three different genetic markers in a marine mammal metapopulation
}

\author{
J. I. Hoffman \\ University of Cambridge \\ K. K. Dasmahapatra \\ University College London \\ W. Amos \\ University of Cambridge \\ C. D. Phillips \\ Center for the Environment, Purdue University \\ T. S. Gelatt \\ National Marine Fisheries Service, Alaska Fisheries Science Centre \\ See next page for additional authors
}

Follow this and additional works at: https://digitalcommons.unl.edu/usdeptcommercepub

Part of the Environmental Sciences Commons

Hoffman, J. I.; Dasmahapatra, K. K.; Amos, W.; Phillips, C. D.; Gelatt, T. S.; and Bickham, J . W., "Contrasting patterns of genetic diversity at three different genetic markers in a marine mammal metapopulation" (2009). Publications, Agencies and Staff of the U.S. Department of Commerce. 202.

https://digitalcommons.unl.edu/usdeptcommercepub/202

This Article is brought to you for free and open access by the U.S. Department of Commerce at DigitalCommons@University of Nebraska - Lincoln. It has been accepted for inclusion in Publications, Agencies and Staff of the U.S. Department of Commerce by an authorized administrator of DigitalCommons@University of Nebraska - Lincoln. 


\section{Authors}

J. I. Hoffman, K. K. Dasmahapatra, W. Amos, C. D. Phillips, T. S. Gelatt, and J . W. Bickham

This article is available at DigitalCommons@University of Nebraska - Lincoln: https://digitalcommons.unl.edu/ 


\title{
Contrasting patterns of genetic diversity at three different genetic markers in a marine mammal metapopulation
}

\author{
J. I. HOFFMAN, ${ }^{*}$ K. K. DASMAHAPATRA,+ W. AMOS,${ }^{*}$ C. D. PHILlips,$\ddagger$ T. S. GELATT§ and \\ J. W. BICKHAM† \\ *Department of Zoology, University of Cambridge, Downing Street, Cambridge CB2 3EJ, UK, +Galton Laboratory, Department of \\ Genetics, Evolution and Environment, University College London, 4 Stephenson Way, London NW1 2HE, UK, $\ddagger$ Center for the \\ Environment, Purdue University, West Lafayette, IN 47907, USA, §National Marine Fisheries Service, Alaska Fisheries Science Centre, \\ 7600 Sand Point Way, NE, Building 4, Seattle, WA 99815-6349, USA
}

\begin{abstract}
Many studies use genetic markers to explore population structure and variability within species. However, only a minority use more than one type of marker and, despite increasing evidence of a link between heterozygosity and individual fitness, few ask whether diversity correlates with population trajectory. To address these issues, we analysed data from the Steller's sea lion, Eumetiopias jubatus, where three stocks are distributed over a vast geographical range and where both genetic samples and detailed demographic data have been collected from many diverse breeding colonies. To previously published mitochondrial DNA (mtDNA) and microsatellite data sets, we have added new data for amplified fragment length polymorphism (AFLP) markers, comprising 238 loci scored in 285 sea lions sampled from 23 natal rookeries. Genotypic diversity was low relative to most vertebrates, with only 37 loci $(15.5 \%)$ being polymorphic. Moreover, contrasting geographical patterns of genetic diversity were found at the three markers, with Nei's gene diversity tending to be higher for AFLPs and microsatellites in rookeries of the western and Asian stocks, while the highest mtDNA values were found in the eastern stock. Overall, and despite strongly contrasting demographic histories, after applying phylogenetic correction we found little correlation between genetic diversity and either colony size or demography. In contrast, we were able to show a highly significant positive relationship between AFLP diversity and current population size across a range of pinniped species, even though equivalent analyses did not reveal significant trends for either microsatellites or mtDNA.

Keywords: amplified fragment length polymorphism (AFLP), conservation genetics, demography, Eumetopias jubatus, genetic diversity, microsatellite, mtDNA, phylogeography, pinniped, Steller's sea lion, stock structure

Received 5 January 2009; revision received 7 April 2009; accepted 9 April 2009
\end{abstract}

\section{Introduction}

Molecular genetic analysis of population structure is now a commonplace tool in the armoury of those wishing to understand the dynamics of natural populations. Currently, two classes of marker dominate those used in this context: maternally inherited mitochondrial DNA (mtDNA) and presumed neutral microsatellites (Zhang \& Hweitt 2003; Schlotterer 2004). These markers provide

Correspondence: Joseph I. Hoffman, Fax: +44 1223336676;

E-mail:jih24@cam.ac.uk contrasting views of a given scenario, the mitochondrial sequences allowing reconstruction of maternal lineages while the microsatellites give a joint window of both maternal and paternal contributions. When combined, these contrasting views can become synergistic, with the mitochondrial markers uncovering patterns of maternally directed natal site fidelity, while the microsatellites help to quantify levels of paternal gene flow among subpopulations (e.g. Waits et al. 2000; Miller-Butterworth et al. 2003). Given this, it is perhaps surprising that studies combining both markers are the exception rather than the rule. 
In addition to differences in mode of inheritance, markers can also differ in their rate of evolution. Mitochondrial sequences tend to evolve faster than nuclear sequences while microsatellites evolve much faster than, for example, protein isozymes (e.g. Ellegren 2000; Ballard \& Whitlock 2004; Schlotterer 2004). Rapidly evolving markers tend to be most useful for capturing recent demographic patterns and generally offer greater resolution due to their higher allelic/haplotypic diversities but may saturate over longer periods of time (Selkoe \& Toonen 2006). However, deeper patterns such as residual signals of glacial refugia could potentially benefit from the use of more slowly evolving markers such as amplified fragment length polymorphisms (AFLPs). Arguably, even fewer studies compare markers that evolve over different timescales relative to those that compare nuclear and mitochondrial markers.

The primary aim of many studies of this nature is to understand current patterns of gene flow and genetic diversity in the context of historical patterns of demographic expansion and contraction, for example by identifying putative population bottlenecks or vicariant events that created isolated subpopulations. However, recent work has highlighted the possible importance of genetic diversity in determining the health of both individuals (e.g. Coltman et al. 1999; Acevedo-Whitehouse et al. 2003) and perhaps by implication, populations. Indeed, a long-standing question in conservation genetics concerns the extent to which populations carrying high genetic diversity perform in some sense better than populations with low diversity, either as a consequence of identified bottlenecks or perhaps as an inherent property of a species. Here, use of contrasting types of markers is desirable, since it is quite possible for high, recently acquired microsatellite diversity to mask longer-term patterns in the underpinning additive genetic variability upon which selection is most likely to act.

Little is currently known about the link between genetic diversity and fitness at the population level, although relatively heterozygous vertebrate populations have been shown to experience lower parasite loads (Whiteman et al. 2006), improved body condition (Knaepkens et al. 2002), faster growth rates (Rowe et al. 1999; Cena et al. 2006) and greater survivorship (Saccheri et al. 1998; Shikano \& Taniguchi 2002; Andersen et al. 2004). A recent meta-analysis of both plant and animals (Reed \& Frankham 2003) suggests that genetic diversity could explain as much as $15-20 \%$ of variation in population fitness. However, the majority of studies to date have used allozymes, which may not be selectively neutral. In addition, although heterozygosity has been linked to a number of population fitness traits, surprisingly few studies have looked for a link between genetic diversity and the rate at which natural populations grow or decline.

Although a positive relationship between population heterozygosity and viability seems intuitive, it may not always be that simple. Two recent studies have examined how levels of heterozygosity vary during the course of welldocumented demographic challenges. Vazquez-Dominguez et al. (1999) found that heterozygosity increased during population declines in the spiny pocket mouse, and Valsecchi et al. (2004) found that Mediterranean striped dolphins dying early in an epizootic were significantly less heterozygous than those dying later. These studies imply that natural selection may sometimes remove relatively homozygous individuals from populations during demographic declines, raising the counter-intuitive possibility that, at least in the short term, declining populations may in fact be more heterozygous than stable ones. Furthermore, the purging of genetic load during population bottlenecks could generate a scenario in which relatively homozygous populations do well in the face of challenges.

The Steller's sea lion, Eumetopias jubatus, provides an opportunity to explore range-wide patterns of genetic diversity and to study the relationship between genetic variation and population viability in a natural metapopulation of a vertebrate species. The largest of the extant otariids, this species is distributed across the North Pacific Rim and throughout the Bering and Okhotsk Seas (Fig. 1). The worldwide population was once estimated to number about a quarter of a million animals (Kenyon \& Rice 1961), but by 1989 the count had fallen to a little over 100000 (Loughlin et al. 1992). This steep decline attracted worldwide attention and led to the Steller's sea lion being listed as Threatened under the US Endangered Species Act in 1990. Genetic studies using mtDNA (e.g. Bickham et al. 1996) led to the recognition of two well-differentiated stocks, eastern and western, which were listed as Threatened (eastern) and Endangered (western) in 1997. Subsequently, a larger study using mtDNA argued for the partitioning of the western stock to yield an additional Asian stock. Biparentally inherited microsatellite markers yield qualitatively similar findings (Hoffman et al. 2006), but also suggest that two genetically distinct subpopulations may exist within the western stock (O'Corry-Crowe et al. 2007). More recently, on the basis of morphological differences between skulls from the western and eastern stocks, Philips et al. (in press) elevated these to subspecies, designated the western Steller's sea lion (Eumetopias jubatus jubatus) and Loughlin's northern sea lion (Eumetopias jubatus monteriensis), respectively.

The reasons why certain Steller's sea lion populations have experienced a precipitous decline while others have remained stable or even increased are not readily apparent. Suggested causes of the decline include changes in food availability caused by overfishing and/ or a regime shift in the North Pacific Ocean, legal and illegal shooting and predation (Loughlin \& York 2000; Atkinson et al. 2008). Whatever the reason or reasons might be, it is clear from the highly subdivided nature 


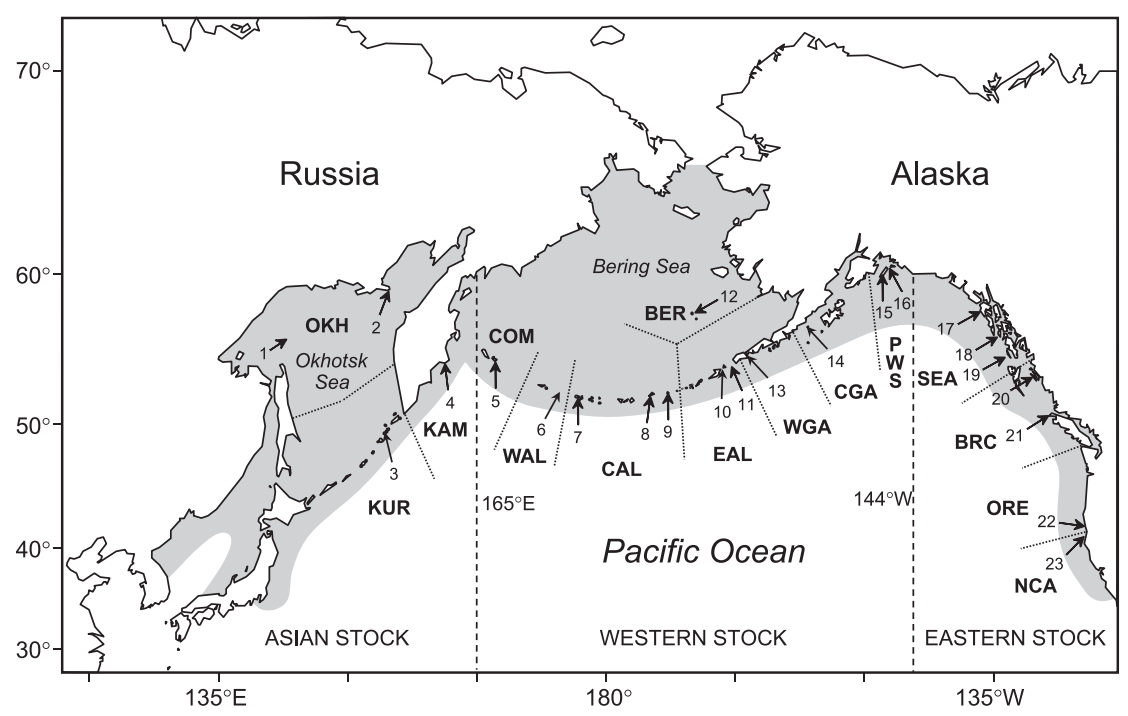

Fig. 1 Map showing the locations of 23 Steller's sea lion rookeries sampled in this study. The grey area indicates the current distribution of the species. Stocks and regions are as defined by Baker et al. (2005). For details of regions and rookeries, including the numbers of individuals genotyped, see Table 1. of this metapopulation that the extirpation of rookeries could lead to an erosion of overall genetic variability within the species.

Here we analyse a data set comprising 285 Steller's sea lions genotyped at AFLP loci together with previously published data sets for microsatellites (598 individuals genotyped at 13 loci) and mtDNA (1559 individuals sequenced at 238 bp of D-loop HVR-1). Our aims were to assess overall levels of genetic diversity, to test whether AFLPs show the same signal of genetic structure as the other two marker types, to examine the relationship between genetic diversity and both colony size and rate of decline, and finally to place observed levels of genetic diversity in the context of other pinniped species.

\section{Materials and methods}

\section{Tissue sample collection and DNA extraction}

We utilized 285 tissue samples that were collected as part of a previous study (Baker et al. 2005) from pups at their natal rookeries ranging from Iony Island in the Okhotsk Sea to St. George Reef in northern California (Table 1, Fig. 1). Samples were obtained from rear flipper punches and stored individually in the preservative buffer $20 \%$ dimethyl sulphoxide (DMSO) saturated with salt. Total genomic DNA was extracted using a standard phenol-chloroform protocol (Sambrook et al. 1989).

\section{AFLP genotyping}

The AFLP protocol was similar to that used by Vos et al. (1995) and is described in detail by Dasmahapatra et al. (online early). Briefly, 100-400 ng of genomic DNA was first digested using Taq $\mathrm{I}\left(5 \mathrm{U}\right.$ in a $10-\mu \mathrm{L}$ volume at $65{ }^{\circ} \mathrm{C}$ for
$2 \mathrm{~h}$ ) and then with EcoRI ( $5 \mathrm{U}$ in a $20-\mu \mathrm{L}$ volume at $37{ }^{\circ} \mathrm{C}$ for $2 \mathrm{~h}$ ). TaqI and EcoRI adapters were then ligated onto the digested DNA using T4 DNA ligase ( $1 \mathrm{U}$ in a $50-\mu \mathrm{L}$ volume at $37{ }^{\circ} \mathrm{C}$ for $3 \mathrm{~h}$ ), and the resulting products diluted 10 -fold in $10 \mathrm{~mm}$ Tris- $\mathrm{HCl}$ and EDTA (0.1 mm, $\mathrm{pH} 8.0)$. For the pre-amplification, $5 \mu \mathrm{L}$ of ligation mix was added to $50 \mu \mathrm{L}$ polymerase chain reaction (PCR) containing Tris- $\mathrm{HCl}$ (10 mm, pH 8.3), $\mathrm{MgCl}_{2}$ (1.5 mM), $\mathrm{KCl}$ (50 mM), dNTPs $(0.2 \mathrm{~mm}), \mathrm{Taq}$ polymerase $(1 \mathrm{U})$ and $50 \mathrm{ng}$ each of the TaqI-C and EcoRI-A pre-amplification primers (the primer sequences were 5'-GATGAGTCCTGACCGAC-3' and 5'-GACTGCGTACCAATTCA-3', respectively). Following 30 pre-amplification cycles $\left(30\right.$ s at $94{ }^{\circ} \mathrm{C}, 60$ s at $50{ }^{\circ} \mathrm{C}$ and $60 \mathrm{~s}$ at $72{ }^{\circ} \mathrm{C}$ ), the products were diluted 10-fold with $10 \mathrm{~mm}$ Tris- $\mathrm{HCl}$ and EDTA (0.1 mm, pH 8.0). For the selective amplification, $2.5 \mu \mathrm{L}$ of the diluted pre-amplification product was added to a $12.5-\mu \mathrm{L}$ reaction containing Tris- $\mathrm{HCl}$ (10 mm, pH 8.3), $\mathrm{MgCl}_{2}$ (1.5 mM), $\mathrm{KCl}$ (50 mm), dATPs, dTTP amd dGTP (0.2 mm each), dCTP (0.04 mm), $\alpha^{33} \mathrm{P}-\mathrm{dCTP}$, Taq polymerase (0.2 U), TaqI selective primer (30 ng) and EcoRI selective primer (5 ng). Samples were subjected to 13 selective amplification cycles (30 s at $94{ }^{\circ} \mathrm{C}, 60 \mathrm{~s}$ at $65{ }^{\circ} \mathrm{C}$, reducing by $0.7{ }^{\circ} \mathrm{C}$ each cycle, and $60 \mathrm{~s}$ at $72{ }^{\circ} \mathrm{C}$ ), followed by a further 23 cycles ( $30 \mathrm{~s}$ at $94{ }^{\circ} \mathrm{C}, 60 \mathrm{~s}$ at $56{ }^{\circ} \mathrm{C}$ and $60 \mathrm{~s}$ at $72{ }^{\circ} \mathrm{C}$ ). PCR products were resolved by electrophoresis on standard $6 \%$ polyacrylamide sequencing gels and detected by autoradiography. AFLP profiles were assessed and scored manually by an experienced operator (J.H.). Only clear, polymorphic bands that could be scored in all individuals were included, these being recorded as 1, present and 0, absent. Eight different selective primer combinations were used (Table 2) to generate 238 AFLP loci that could be scored unambiguously across all of the samples.

Although AFLPs tend to be highly reproducible (Vos et al.1995; Jones et al.1997), as with other genetic markers 
Table 1 Numbers of Steller's sea lion samples genotyped at AFLPs, microsatellites and mtDNA control region (see methods for details). Stocks and regions are as defined by Baker et al. (2005)

\begin{tabular}{|c|c|c|c|c|c|}
\hline \multirow[b]{2}{*}{ Stock } & \multirow[b]{2}{*}{ Region } & \multirow[b]{2}{*}{ Rookery } & \multicolumn{3}{|c|}{ Number of samples genotyped } \\
\hline & & & AFLPs & Microsatellites & mtDNA \\
\hline \multirow[t]{4}{*}{ Asian } & Sea of Okhotsk-OKH & 1. Iony Island & 15 & 25 & 100 \\
\hline & & 2. Yamsky Island & 15 & 25 & 80 \\
\hline & Kuril Islands-KUR & 3. Lovushki Island & 10 & 15 & 39 \\
\hline & Kamchatka Peninsula-KAM & 4. Kozlova Cape & 10 & 25 & 59 \\
\hline \multirow[t]{12}{*}{ Western } & Commander Islands-COM & 5. Medny Island & 15 & 25 & 126 \\
\hline & Western Aleutian Islands-WAL & 6. Buldir Island & 9 & 12 & 45 \\
\hline & Central Aleutians-CAL & 7. Kiska Island & 25 & 24 & 72 \\
\hline & & 8. Seguam Island & 10 & 24 & 31 \\
\hline & & 9. Yunaska Island & 10 & 22 & 40 \\
\hline & Eastern Aleutian Islands-EAL & 10. Akutan Island & 10 & 56 & 85 \\
\hline & & 11. Ugamak Island & 10 & 100 & 99 \\
\hline & Bering Sea-BER & 12. Walrus Island & 10 & 13 & 42 \\
\hline & Western Gulf of Alaska-WGA & 13. Clubbing Rocks & 10 & 19 & 35 \\
\hline & Central Gulf of Alaska-CGA & 14. Chowiet Island & 10 & 25 & 32 \\
\hline & Prince William Sound-PWS & 15. Fish Island & 10 & 25 & 47 \\
\hline & & 16. Seal Rocks & 10 & 50 & 102 \\
\hline \multirow[t]{7}{*}{ Eastern } & Southeastern Alaska-SEA & 17. White Sisters Island & 15 & 9 & 49 \\
\hline & & 18. Hazy Island & 10 & 26 & 103 \\
\hline & & 19. Forrester Island & 15 & 10 & 215 \\
\hline & British Columbia-BRC & 20. N. Danger Rocks & 10 & 10 & 10 \\
\hline & & 21. Triangle Island & 10 & 8 & 13 \\
\hline & Oregon-ORE & 22. Rogue Reef & 16 & 25 & 84 \\
\hline & Northern California-NCA & 23. St. George Reef & 20 & 25 & 51 \\
\hline Entire range & & & 285 & 598 & 1559 \\
\hline
\end{tabular}

Table 2 Numbers of AFLP loci generated by eight AFLP selective primer combinations

\begin{tabular}{llcl}
\hline TaqI primer $\left(5^{\prime}-3^{\prime}\right)$ & EcoRI primer $\left(5^{\prime}-3^{\prime}\right)$ & Total no. of loci & No. of polymorphic loci \\
\hline GATGAGTCCTGACCGA-CAC & GACTGCGTACCAATTC-AGC & 33 & 7 \\
GATGAGTCCTGACCGA-CAG & GACTGCGTACCAATTC-ATG & 31 & 6 \\
GATGAGTCCTGACCGA-CGA & GACTGCGTACCAATTC-ACA & 16 & 3 \\
GATGAGTCCTGACCGA-CCA & GACTGCGTACCAATTC-AAC & 29 & 3 \\
GATGAGTCCTGACCGA-CCA & GACTGCGTACCAATTC-AGC & 24 & 4 \\
GATGAGTCCTGACCGA-CCA & GACTGCGTACCAATTC-ATG & 33 & 4 \\
GATGAGTCCTGACCGA-CTG & GACTGCGTACCAATTC-ATG & 40 & 4 \\
GATGAGTCCTGACCGA-CAG & GACTGCGTACCAATTC-ACA & 32 & 6 \\
Total & & 238 & 37 \\
\hline
\end{tabular}

genotyping errors can easily accrue (Bonin et al. 2004; Hoffman \& Amos 2005; Pompanon et al. 2005; Meudt \& Clarke 2007). Consequently, we estimated the genotyping error rate for our data set by independently regenotyping and blind scoring 24 individuals (almost $10 \%$ of the samples). The error rate per reaction was quantified following Bonin et al. (2004) as the number of mismatching genotypes divided by the number of bands compared.

\section{Data analysis}

The final AFLP character matrix consisted of 67830 binary characters representing the presence and absence genotypes of 285 individuals at 238 loci. To examine patterns of genetic structure, we used the program AFLP-SURV version 1.0 (Vekemans 2002) to calculate pairwise $F_{\mathrm{ST}}$ values among rookeries and regions, to generate $F_{\mathrm{ST}}$ matrices for each of 
1000 bootstrapped data sets, and to conduct a permutation test for overall genetic differentiation using 10000 permutations of the data set. A consensus neighbour-joining (NJ) tree was then generated using the Neighbour, Consense and Fitch modules in PHYLIP (Felsenstein 1993). The significance of the correlation between pairwise geographical and genetic distance matrices was assessed using Mantel tests with 10000 iterations implemented in the Mantel Nonparametric Test Calculator version 2.0 (Liedloff 1999). To explore range-wide patterns of genetic diversity, Nei's gene diversity was calculated for each rookery using AFLP-SURV (Vekemans 2002).

We next conducted a Bayesian cluster analysis using Structure 2.2.3 (Pritchard et al. 2000; Falush et al. 2007). This program uses an iterative approach to cluster the genotypes into $K$ populations without knowledge of the population membership of individuals. The approach essentially subdivides the data set in a way that maximizes HardyWeinberg equilibrium and linkage equilibrium within the resulting clusters. The membership of each individual in a population is then estimated as $q$, which varies between 0 and 1 with the latter indicating full population membership. We ran five independent runs for $K=1-10$ using $1 \times 10^{6}$ Markov chain Monte Carlo (MCMC) iterations after a burn-in of $1 \times 10^{5}$, specifying the correlated allele frequencies model and assuming admixture. The most likely number of populations was evaluated using both the maximal value of $\operatorname{Ln} P(D)$, a model-choice criterion that estimates the posterior probability of the data, and $\Delta K$, an ad hoc statistic based on the second order rate of change of the likelihood function with respect to $K$ (Evanno et al. 2005).

To enable comparisons across markers, we also analysed data from 13 highly polymorphic microsatellites ( $n=598$, Hoffman et al. 2006) and from a 238-bp section of the mitochondrial D-loop HVR-1 region ( $n=1559$, Baker et al. 2005; J. W. Bickham, unpublished data). The three data sets overlapped considerably, with the individuals typed at AFLPs being a subset of those genotyped for microsatellites, which were in turn a subset of the much larger sample of individuals typed for mtDNA. Genetic differentiation among rookeries was estimated at both of these markers using Wright's F-statistics (Wright 1951) calculated in Arlequin 2.0 (Schneider et al. 2000). In addition, in response to recent concerns raised about the reliability of $F_{\mathrm{ST}}$ in highly polymorphic systems, we also calculated $D$ for our microsatellite data set following the method of Jost (2008), equation 14 . Overall, results using this approach were very similar to, but less significant than those obtained using classical $F_{\mathrm{ST}}$, suggesting that $F_{\mathrm{ST}}$ has adequate resolution in our system. For comparability with other studies, we therefore used $F_{\mathrm{ST}}$. Nei's gene diversity was also calculated for microsatellites using FSTAT 2.9.3 (Goudet 1995) and for mtDNA using DNAsp (Rojas \& Rojas 1995).
To explore the relationships between genetic diversity at each of the three markers and population size, we constructed a series of general linear models (GLMs). Population sizes were $\log$ transformed both to minimize heteroscedasticity and because population growth trajectories tend to be exponential. Population size estimates were available for the period 1957-2006 inclusive, but the number and timing of records for each of the rookeries varies greatly, from as few as five to as many as 35 observations (Table 3). To standardize our procedure, we therefore defined two critical years: 1960, reflecting the best balance between a date before the declines begin yet where data coverage is still adequate, and 2006, reflecting the current status. For each of these two time points, we estimated the most likely population size by means of linear extrapolation/interpolation in plots of log (population size) on year using all available data for that colony. The $r^{2}$ values of the regressions are shown in Table 3 and averaged 0.614. Population size estimates are, of necessity, somewhat crude but visual inspection of the graphs suggests they are adequate for our purposes. Initially, we constructed GLMs of gene diversity at each of the three different markers fitting $\log$ (population size) as a continuous predictor variable. However, because of the presence of three genetically distinct stocks with on average very different population trajectories (the eastern population was originally small but is now increasing, while the Asian and western stocks were initially large but have since declined), we also constructed additional GLMs of gene diversity fitting both log (population size) and stock, the latter as a factor with three levels corresponding to the Asian, Western and Eastern stocks.

Next, to explore relationships between genetic diversity and the rates at which different Steller's sea lion rookeries have declined, we calculated the growth trajectory of each rookery as the log of the gradient of year on population size. We then constructed GLMs of growth trajectory fitting gene diversity as a single, continuous explanatory variable. As with the GLMs of genetic diversity, we then additionally controlled for stock membership by fitting stock as an additional predictor variable (as a factor with three levels) in GLMs of growth trajectory. All GLMs were fitted using $\mathrm{R}$ ( $\mathrm{R}$ development team 2005) as full models and then simplified following Crawley (2002) by stepwise deletion of non-significant terms (strictly, terms whose deletion did not cause a significant reduction in the proportion of the null deviance explained by the model).

Next, we used two different approaches implemented in the program Bottleneck 1.2.02 (Piry et al. 1999) to test whether any of the three Steller's sea lion stocks have experienced a recent reduction in effective population size or a genetic bottleneck. The first of these approaches exploits the fact that during a bottleneck, alleles are lost more rapidly than heterozygosity at neutral markers, generating a transient 'heterozygosity excess'. This was assessed using the micro- 
Table 3 Summary of population size estimate data for 23 Steller's sea lion rookeries spanning the period 1957-2006 inclusive. The gradient and $r^{2}$ values refer to the regressions of time on log population size, with positive gradients indicating population growth and negative gradients indicating decline

\begin{tabular}{|c|c|c|c|c|c|c|}
\hline Stock & Rookery & No. of observations & First observation & Last observation & Gradient & $r^{2}$ \\
\hline \multirow[t]{4}{*}{ Asian } & Iony Island & 7 & 1974 & 2002 & 0.010 & 0.661 \\
\hline & Yamsky Island & 12 & 1974 & 2003 & 0.006 & 0.397 \\
\hline & Lovushki Island & 23 & 1967 & 2001 & -0.012 & 0.361 \\
\hline & Kozlova Cape & 17 & 1982 & 2003 & -0.021 & 0.420 \\
\hline \multirow[t]{12}{*}{ Western } & Medny Island & 35 & 1967 & 2002 & -0.024 & 0.703 \\
\hline & Buldir Island & 13 & 1968 & 2004 & -0.058 & 0.942 \\
\hline & Kiska Island & 12 & 1979 & 2004 & -0.048 & 0.858 \\
\hline & Seguam Island & 12 & 1979 & 2004 & -0.028 & 0.506 \\
\hline & Yunaska Island & 13 & 1979 & 2006 & -0.033 & 0.779 \\
\hline & Akutan Island & 21 & 1965 & 2006 & -0.024 & 0.726 \\
\hline & Ugamak Island & 18 & 1969 & 2006 & -0.028 & 0.579 \\
\hline & Walrus Island & 5 & 1982 & 1994 & -0.054 & 0.881 \\
\hline & Clubbing Rocks & 18 & 1957 & 2006 & -0.007 & 0.460 \\
\hline & Chowiet Island & 15 & 1957 & 2004 & -0.029 & 0.829 \\
\hline & Fish Island & 15 & 1957 & 2006 & -0.017 & 0.638 \\
\hline & Seal Rocks & 16 & 1973 & 2006 & -0.016 & 0.537 \\
\hline \multirow[t]{7}{*}{ Eastern } & White Sisters Island & 13 & 1979 & 2004 & 0.006 & 0.301 \\
\hline & Hazy Island & 13 & 1979 & 2005 & 0.015 & 0.889 \\
\hline & Forrester Island & 12 & 1979 & 2005 & 0.004 & 0.235 \\
\hline & North Danger Rocks & 9 & 1971 & 2002 & 0.013 & 0.633 \\
\hline & Triangle Island & 7 & 1971 & 2998 & 0.012 & 0.874 \\
\hline & Rogue Reef & 23 & 1977 & 2001 & 0.016 & 0.782 \\
\hline & St. George Reef & 11 & 1990 & 2001 & 0.010 & 0.140 \\
\hline
\end{tabular}

satellite data set for each of the stocks separately under a range of mutation models ranging from the infinite allele model (IAM) through the two-phase mutation model (TPM) with 70\%, 90\%, 95\% and 99\% single-step mutations (with a variance of $30 \%$ ), to the stepwise-mutation model (SMM). Statistical significance was assessed using the Wilcoxon test. The second test implemented using Bottleneck was one for a shift away from an L-shaped allele frequency distribution to one with fewer alleles in low frequency categories (Luikart \& Cornuet 1997).

Finally, we analysed genetic diversity in a representative panel of other pinnipeds, both to provide a context for interpreting the diversity seen in our focal species, and also to learn the extent to which the levels of diversity exhibited by our three classes of marker correlate with likely demographic history. Our panel of species includes some that have been heavily exploited to near extinction and either recovered or stayed endangered, and others that have expanded greatly to become some of the most abundant large mammals on the planet. For this analysis, we collated published and unpublished data on microsatellites, mitochondrial D-loop sequences and AFLP markers from as many pinniped species as were available (Table 4). Recognized subspecies were treated separately, as were the Western and Eastern Atlantic populations of the grey seal, Halichoerus grypus. To avoid ascertainment bias, micro- satellite data were only accepted if based on markers that were derived from the species being analysed. We also excluded markers that were out of Hardy-Weinberg equilibrium and/or exhibited high frequencies of null alleles. For each of 12 species/subspecies, average observed heterozygosity was calculated over all of the microsatellites that met our criteria. Mitochondrial D-loop sequences (with the 5' end of tRNA-Pro) together with haplotype frequencies were available for 19 species/subspecies. For these species, a section corresponding to positions 39-327 in the Arctocephalus pusillus mitochondrial genome (AM181018) was used to calculate haplotype diversity. The length of sequence varied among the species due to the presence of indels and in some cases, only sequence data for a slightly shorter section were available. Within each species, sequences were aligned using ClustalW and by eye, and sequence diversity $\pi$ (Nei 1987) was calculated using MEGA 4 (Tamura et al. 2007). AFLP genotypes were generated for 14 different pinniped species for which adequate samples were available. We chose a target sample number of five as the best compromise between generating representative profiles and including as many species as possible. Five is probably too small for many classes of marker, but for AFLPs the low sample size is partly compensated for by the large number of traits (= bands) that can be scored. AFLP diversity was calculated as the 
Table 4 Genetic diversity at AFLP markers (proportion of polymorphic loci), microsatellites (observed heterozygosity) and mtDNA control region sequence diversity in a variety of pinniped species

\begin{tabular}{|c|c|c|c|c|}
\hline Family & Species & $\begin{array}{l}\text { Proportion of } \\
\text { polymorphic } \\
\text { AFLP loci }\end{array}$ & $\begin{array}{l}\text { Observed microsatellite } \\
\text { heterozygosity (no. of } \\
\text { loci, no. of samples) }\end{array}$ & $\begin{array}{l}\text { Sequence diversity, } \pi \text {, } \\
\text { at mtDNA D-loop } \\
\text { (sequence length used, } \\
\text { no. of samples) }\end{array}$ \\
\hline \multirow[t]{14}{*}{ Phocidae } & Crabeater seal, Lobodon carcinophaga & - & $0.813(6,25)^{1}$ & - \\
\hline & $\begin{array}{l}\text { Grey seal, Halichoerus grypus } \\
\text { (Eastern Atlantic population) }\end{array}$ & 0.133 & $0.784(5,805)^{2}$ & $0.014(327,1025)^{3}$ \\
\hline & Eastern Atlantic Harbour seal, Phoca vitulina vitulina & 0.056 & $0.238(6,50)^{4}$ & $0.0054(320,159)^{5}$ \\
\hline & Western Atlantic Harbour seal, Phoca vitulina concolour & - & $0.390(5,>40)^{6}$ & $0.012(320,18)^{5}$ \\
\hline & Eastern Pacific Harbour seal, Phoca vitulina richardsi & - & - & $0.014(320,38)^{5}$ \\
\hline & Western Pacific Harbour seal, Phoca vitulina stejnegeri & - & - & $0.015(320,12)^{5}$ \\
\hline & Harp seal, Pagophilus groenlandicus & 0.215 & - & - \\
\hline & Hawaiian monk seal, Monachus schauinslandi & - & - & $0.0001(337,50)^{7}$ \\
\hline & Hooded seal, Cystophora cristata & 0.168 & - & $0.030(334,123)^{8}$ \\
\hline & Leopard seal, Hydrurga leptonyx & 0.144 & $0.626(7,21)^{1}$ & - \\
\hline & Northern elephant seal, Mirounga angustirostris & - & - & $0.004(299,150)^{9,}, 10$ \\
\hline & Southern elephant seal, Mirounga leonina & 0.066 & $0.597(2,263)^{10}$ & $0.021(301,48)^{10}$ \\
\hline & Spotted seal, Phoca largha & - & - & $0.024(335,66)^{11}$ \\
\hline & Weddell seal, Leptonychotes weddellii & - & $0.737(17,96)^{1}$ & - \\
\hline \multirow[t]{12}{*}{ Otariidae } & Antarctic fur seal, Arctocephalus gazella & 0.113 & $0.744(15,20)^{12,13}$ & $0.038(304,192)^{14}$ \\
\hline & Australian Sea lion, Neophoca cinerea & - & - & $0.016(288,194)^{15}$ \\
\hline & California sea lion, Zalophus californianus & 0.109 & $0.602(9,58)^{16}$ & $0.020(283,52)^{17}$ \\
\hline & Cape fur seal, Arctocephalus pusillus & - & - & $0.031(285,105)^{18}$ \\
\hline & Galapagos fur seal, Arctocephalus galapagoensis & 0.055 & - & - \\
\hline & Galapagos sea lion, Zalophus californianus wollebacki & 0.037 & $0.677(15,>20)^{19,20}$ & $0.005(285,336)^{21}$ \\
\hline & Guadalupe fur seal, Arctocephalus townsendi & - & - & $0.021(212,32)^{22}$ \\
\hline & Juan fernandez fur seal, Arctocephalus philippii & - & - & $0.031(298,28)^{23}$ \\
\hline & Northern fur seal, Callorhinus ursinsus & 0.130 & - & - \\
\hline & South American fur seal, Arctocephalus australis & 0.069 & - & - \\
\hline & Steller sea lion, Eumetopias jubatus & 0.063 & $0.507(6,20)^{24}$ & $0.011(196,2599)^{25}$ \\
\hline & Subantarctic fur seal, Arctocephalus tropicalis & - & - & $0.044(299,103)^{26}$ \\
\hline \multirow[t]{2}{*}{ Obeniidae } & Atlantic walrus, Odobenus rosmarus rosmarus & - & $0.800(7,57)^{27 *}$ & - \\
\hline & Pacific walrus, Odobenus rosmarus divergens & 0.152 & - & - \\
\hline
\end{tabular}

1, Davis et al. (2002); 2, Allen et al. (1995); 3, Amos, unpublished data; 4, Coltman et al. (1996); 5, Stanley et al. (1996); 6, Goodman (1997); 7, Kretzmann et al. (1997); 8, Coltman et al. (2007); 9, Weber et al. (2000); 10, Hoelzel et al. (1999); 11, Mizuno et al. (2003); 12, Hoffman et al. (2008); 13, Hoffman (online early); 14, Hoffman, unpublished data; 15, Campbell (2003); 16, Hernandez-Velazquez et al. (2005);

17, Maldonado et al. (1995); 18, Mathee et al. (2006); 19, Wolf et al. (2005); 20, Hoffman et al. (2007); 21, Wolf, unpublished data; 22 , Weber et al. (2004); 23, Goldsworthy et al. (2000); 24, Huebinger et al. (2007); 25, Bickham, unpublished data; 26, Wynen et al. (2000); 27, Buchanan et al. (1998); *data from Foxe Basin population but similar observed microsatellite heterozygosity values were also found for a range of other populations by Andersen et al. (1998).

proportion of polymorphic bands. Population size estimates were obtained from the Seal Conservation Society website (www.pinnipeds.org) and where a range was given, we took the average of the upper and lower estimates.

Since the taxa (populations and species in the case of intraspecific and interspecific analyses respectively) are related, we also explored the use of phylogenetic correction. For this we chose the program Continuous as implemented in BayesTraits 1.0 (Pagel 1997; Pagel 1999). This program accepts as input a phylogeny plus data from two variables and then uses either a likelihood-based approach or Monte Carlo Markov Chain to estimate the degree to which the variables are correlated given the phylogeny. We chose to implement the likelihood option in which the likelihood of the data given the phylogeny is calculated twice, once under the assumption of independence and a second time under the assumption that a correlation is present. Twice the difference between these likelihoods can then be interpreted as a chi-squared value with one degree of freedom.

\section{Results}

We genotyped 285 Steller's sea lions sampled from 23 natal rookeries representing 15 regions and three stocks (Fig. 1, Table 1) at eight selective AFLP primer combinations, yielding 238 putatively homologous loci (= bands) that could be scored unambiguously (Table 2). The calculated 


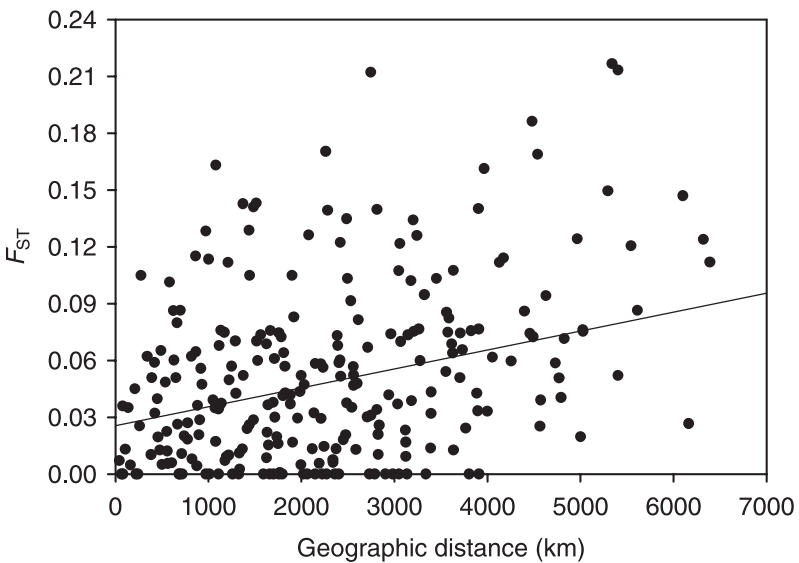

Fig. 2 The relationship between geographical and genetic distance calculated using AFLPs among 23 Steller's sea lion rookeries. The linear regression line is shown to indicate the underlying trend $\left(r^{2}=0.135\right)$.

genotyping error rate was low at 0.012 per band (11 differences observed out of 888 band-band comparisons). Of the discrepancies observed between the two sets of genotypes, four $(36.4 \%)$ were attributed to scoring or data entry errors and the remaining seven $(63.6 \%)$ were due to the stochastic appearance or disappearance of bands as similarly documented by Bonin et al. (2004). Overall, levels of AFLP variability were low, with only 37 out of the 238 loci scored (15.5\%, Table 2) being polymorphic in our large and geographically diverse sample. To facilitate interspecific comparisons, Milot et al. (2007) proposed quantifying AFLP variability using $P_{5 \%}$, the proportion of loci where at least $5 \%$ of individuals carry the minor genotype. $P_{5 \%}$ for our data set is $5.9 \%$, far lower than the normal range of values reported for vertebrates (summarized by Milot $e t$ al. 2007) and is comparable with values obtained for wandering (5.1\%) and Amsterdam (2.1\%) albatrosses which were interpreted by Milot et al. (2007) as being extremely low.

\section{Genetic structure and isolation by distance}

A statistically significant pattern of genetic differentiation was observed across the species range (overall $F_{\mathrm{ST}}$ among rookeries $=0.050, P<0.001$ using 10000 permutations of the AFLP data set). Pairwise $F_{\mathrm{ST}}$ values correlated positively with the geographical distance among rookeries (Fig. 2, Mantel test, $r=0.367, n=23$ colonies, $P<0.001$ ), yielding a similar pattern to that obtained previously using 13 microsatellite loci (Hoffman et al. 2006). Also concordant with previous analysis of the same samples using microsatellites, no relationship between genetic and geographical distance was apparent when only within-stock comparisons were made (Asian stock, Mantel's $r=-0.098$, $n=4, P=0.491$, Western stock, Mantel's $r=0.061, n=12$, (a)

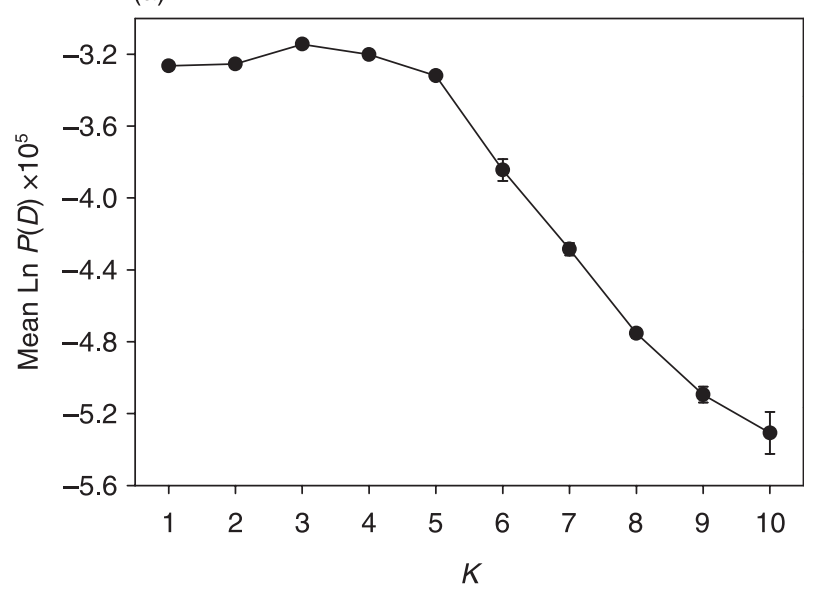

(b)

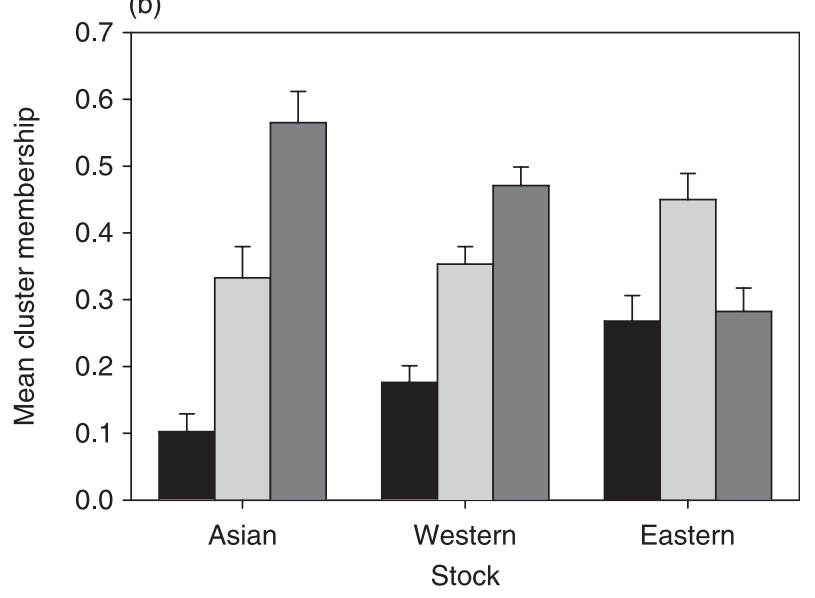

Fig. 3 Results of the Structure analysis of the AFLP data set. (a) Mean \pm SE $\operatorname{Ln} P(D)$ values based on five replicates for each value of $K$; (b) Mean \pm SE cluster membership coefficients for the three clusters (colour coded in black, light grey and dark grey, respectively) for each of the Steller's sea lion stocks.

$P=0.348$, Eastern Stock, Mantel's $r=-0.027, n=7, P=0.486)$ suggesting that the overall pattern is driven by among-stock comparisons. As expected, genetic distances calculated from the AFLP data matrix were positively correlated with equivalent values derived from both microsatellites and mtDNA (Mantel tests, $r=0.371, n=23, P=0.002$ and $r=0.326, n=23, P<0.001$, respectively), suggesting that all three of these markers provide concordant estimates of genetic differentiation. To further explore patterns of genetic divergence, we constructed a neighbour-joining tree at the regional level using 1000 bootstrapped $F_{\mathrm{ST}}$ matrices. The resulting topography was poorly resolved with the majority of nodes failing to gain $50 \%$ or greater bootstrap support, probably because of the small number of informative loci on which the genetic distances are calculated. Nevertheless, the regions of the eastern stock (SEA, BRC, ORE and NCA) form a distinct clade (data not shown), in 
(a) AFLPS

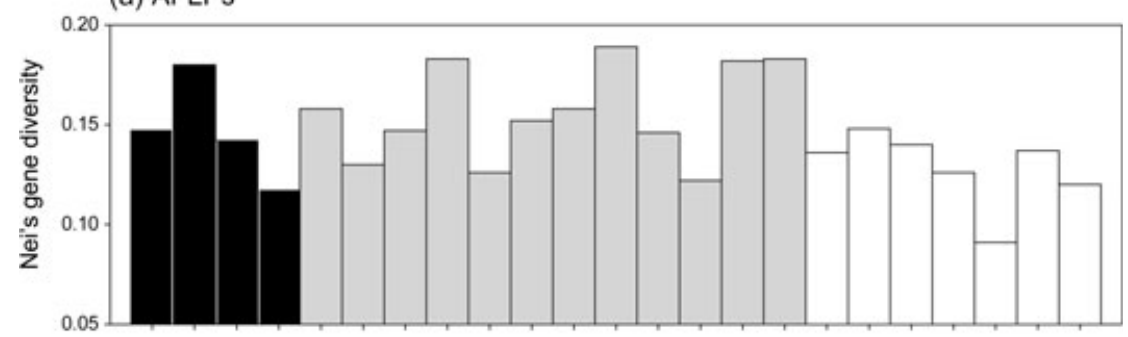

(b) Microsatellites

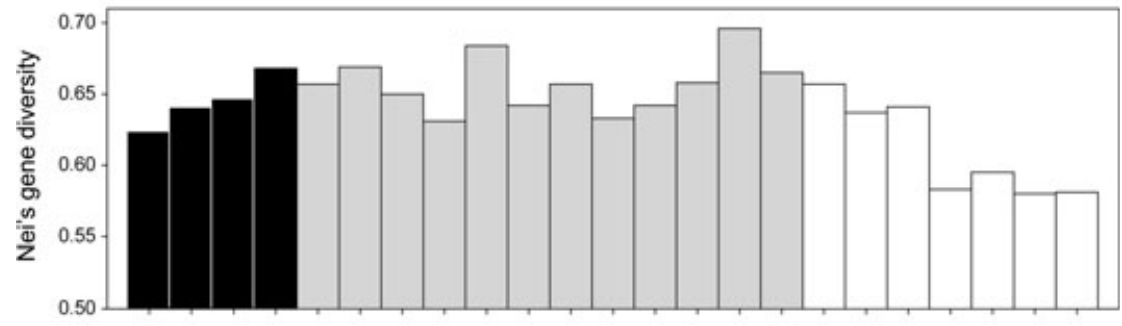

(c) mtDNA

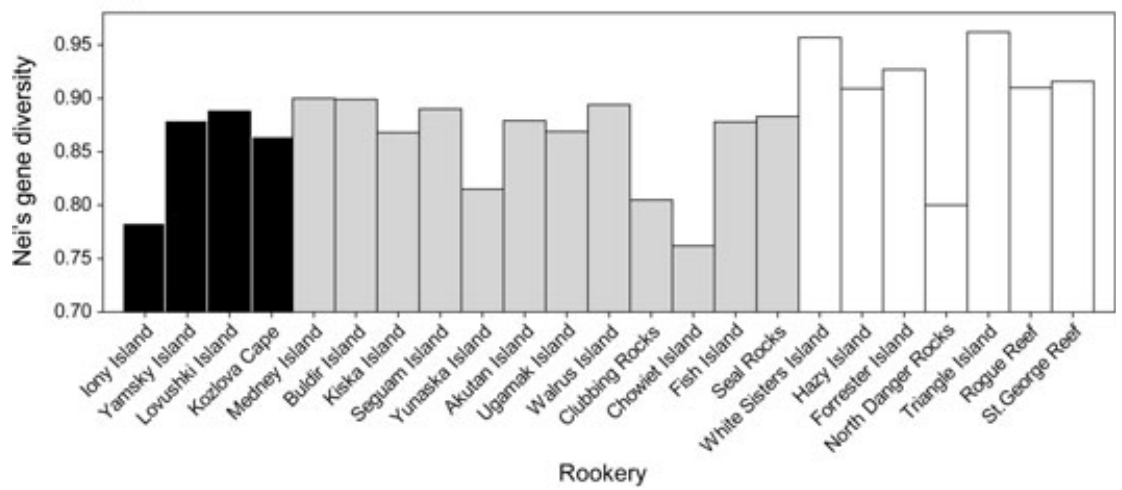

Fig. 4 Geographical variation in Nei's gene diversity across the current range of the Steller's sea lion calculated for (a) AFLPs, (b) microsatellites, and (c) mtDNA. Rookeries of the Asian, Western and Eastern stocks are denoted by black, grey and white-filled bars, respectively. support of previous studies using both mtDNA and microsatellites (Baker et al.2005; Hoffman et al.2006).

\section{Bayesian cluster analysis}

We next implemented a Bayesian cluster analysis of the AFLP data set using the program Structure (Pritchard et al. 2000; Falush et al. 2007) in order to determine whether any genetic substructure could be detected without knowledge of the sampling locations of individuals. The resulting posterior probabilities were highly concordant among replicate runs, with the highest average value indicating the most likely number of population groups, $K$. Our data yielded a best estimate of $K=3$ (Fig. 3a), which was also supported by a peak in Evanno et al.'s (2005) $\Delta K$ statistic. However, despite good support for $K=3$, many individuals were poorly resolved in terms of group membership, probably because of the low resolution afforded by 37 unidominant markers. Consequently, we summarized the data by averaging the group membership coefficients for all individuals in each of the three stocks (Fig. 3b). Average group membership coefficients were found to vary significantly among the stocks (in a two-way ANOVA fitting group, stock and the group:stock interaction, the interaction term was highly significant, $F_{(4,846)}=11.4$, $P<0.0001)$. The first two clusters showed an increase in mean membership progressing from Asian through Western to the Eastern stock, while the third cluster shows the opposite, a pattern that is broadly consistent with isolation by distance.

\section{Genetic diversity, population size and demography}

To explore range-wide patterns of genetic diversity, we calculated Nei's gene diversity for each rookery using each of our three markers: AFLPs, microsatellites and mtDNA (Fig. 4). Significant variation was found among the three stocks for both AFLPs and microsatellites (one-way ANOvAs, $F_{2,20}=3.60, P=0.046$ and $F_{2,20}=8.00, P=0.003$, respectively) with the lowest Nei's gene diversity values 
being found among the rookeries of the Eastern stock at both of these markers. In contrast, mtDNA diversity does not vary significantly among the three stocks (ANOVA, $\left.F_{2,20}=2.95, P=0.075\right)$. Moreover, for mtDNA the six highest gene diversity values all occur in the Eastern stock, the stock which has lowest nuclear diversity.

To relate genetic diversity at the three classes of marker to population size, we regressed gene diversity against log population size in 1960, chosen to reflect the best balance between a date before the declines begin yet where data coverage is still adequate and estimated by linear extrapolation from the available data. Nei's gene diversity was significantly correlated with the estimated population size in 1960 for microsatellites $\left(F_{1,21}=8.14 ; P=0.010\right)$ but not for AFLPs or mtDNA $\left(F_{1,21}=0.35 ; P=0.562\right.$ and $F_{1,21}=$ $0.01 ; P=0.921$, respectively). However, when these regressions were repeated as GLMs of genetic diversity with population size fitted as a continuous variable and stock membership (e.g. Asian, Western or Eastern) fitted as a factor, neither of these terms were retained in the final model for AFLPs and mtDNA (although stock approached significance at $P=0.055$ and 0.075 , respectively), and only stock was retained as a predictor of microsatellite diversity, explaining $45.0 \%$ of the null deviance $\left(F_{2,20}=8.17 ; P=\right.$ 0.003).

Since the 1960s, the Western stock has undergone rapid decline, while the Eastern stock has increased. Consequently, we repeated the same analysis as above but this time fitting log population size in 2006 as a predictor of genetic diversity. Direct population count data were available for six rookeries of the Western Stock, and for the remaining rookeries, population size was obtained by linear extrapolation. AFLP and microsatellite diversity were both negatively associated with population size and mtDNA diversity was weakly but positively associated with population size, although none of these relationships were significant and only microsatellites approached significance $\left(F_{1,21}=4.30 ; P=0.050\right)$. Again, when stock and population size in 2006 were fitted in full models of genetic diversity, no terms were retained for AFLPs and mtDNA, and only stock was retained in the GLM of microsatellite diversity.

Previous studies have found links between genetic diversity and population viability in a range of organisms (e.g. Saccheri et al. 1998; Rowe et al. 1999; Whiteman et al. 2006). Therefore, we sought to establish whether genetic diversity was linked to the rates at which different Steller's sea lion rookeries have declined. Microsatellite diversity explained a significant proportion of the variation in log population trend when fitted alone in a GLM $\left(F_{1,21}=11.17 ; P=0.003\right)$, although the direction was in the reverse direction to that expected (e.g. growing colonies had lower gene diversity). In contrast, AFLPs and mtDNA did not explain significant variation when fitted alone
$\left(F_{1,21}=1.91 ; P=0.180\right.$ and $F_{1,21}=0.53 ; P=0.474$, respectively). Moreover, when full models of log population trend were constructed in which genetic diversity and stock were fitted together as predictors, only stock was retained $\left(F_{2,20}=23.29 ; P<0.0001\right)$, explaining $70.0 \%$ of the total deviance.

To either confirm or refute the above trends, we ignored stock and instead used phylogenetic correction to allow for non-independence among populations. For this analysis, we explored the use of three alternative input phylogenies: (i) based on pooled data from AFLPs, mtDNA and microsatellites in which each pairwise distance was taken as the average of the three marker classes, normalized to force equal contribution from each marker class and with any negative distance values rounded to zero; (ii) what we consider subjectively the 'best' phylogeny, as judged by its ability to place neighbouring populations close to each other, based on the microsatellite $F_{\mathrm{ST}}$ values; and (iii) a non-genetic phylogeny based on great circle geographical distances. In each case and for each marker class, we tested for a correlation between genetic diversity and (i) population size in 1960, (ii) population size in 2006, (iii) the slope of population trend. Unfortunately, the results were highly variable. Using the geographical distance and microsatellite phylogenies, none of the tests were significant (ignoring one case of $P=0.03$ that is best attributable to type I error). In contrast, using the full genetic phylogeny, we find that both AFLP and microsatellite diversity are correlated with population size in 1960 and $2006(P<0.002$ in every case), while mtDNA diversity predicts the overall trend $(P<0.001)$.

\section{Genetic bottleneck analyses}

To determine whether low AFLP diversity in the Steller's sea lion could be at least partly due to a recent reduction in the effective population size, we next interrogated our microsatellite data set using the program Bottleneck (Piry et al. 1999). Significant heterozygosity excess was found in all three stocks using the IAM and within the Asian Stock using the SMM (Table 5). However, little evidence for a bottleneck was found using any of the probably more realistic TPM models. Moreover, none of the stocks deviated significantly from a normal L-shaped distribution of allele frequencies.

\section{Patterns of genetic diversity across the Pinnipedia}

Although $P_{5 \%}$ appears low in the Steller's sea lion relative to most other vertebrates, there are problems in comparing different studies including the use of different restriction enzymes and selective primer combinations, variation in the geographical range of sampling and interobserver variation. Therefore, we sought to place the observed value 
Table 5 Results of heterozygosity excess tests for the three Steller's sea lion stocks under a range of different mutational models using 13 polymorphic microsatellite loci (Hoffman et al. 2006)

\begin{tabular}{|c|c|c|c|c|c|c|c|c|}
\hline \multirow[b]{2}{*}{ Stock } & \multirow[b]{2}{*}{ Test } & & \multicolumn{6}{|c|}{ Mutation model } \\
\hline & & & IAM & TPM 70 & TPM 90 & TPM 95 & TPM 99 & SMM \\
\hline \multirow[t]{4}{*}{ Asian } & No. of loci with heterozygosity excess & & 11 & 10 & 7 & 6 & 5 & 4 \\
\hline & Wilcoxon test & $P$ value (one tail for heterozygosity deficiency) & 0.999 & 0.905 & 0.658 & 0.368 & 0.658 & 0.047 \\
\hline & & $P$ value (one tail for heterozygosity excess) & 0.002 & 0.108 & 0.368 & 0.658 & 0.368 & 0.960 \\
\hline & & $P$ value (two tails) & 0.003 & 30.216 & 0.735 & 0.735 & 0.735 & 0.094 \\
\hline \multirow[t]{4}{*}{ Western } & No. of loci with heterozygosity excess & & 12 & 9 & 8 & 7 & 6 & 6 \\
\hline & Wilcoxon test & $P$ value (one tail for heterozygosity deficiency) & 0.998 & 30.960 & 0.632 & 0.393 & 0.170 & 0.095 \\
\hline & & $P$ value (one tail for heterozygosity excess) & 0.003 & 0.047 & 0.393 & 0.632 & 0.847 & 0.916 \\
\hline & & $P$ value (two tails) & 0.005 & 0.094 & 0.787 & 0.787 & 0.339 & 0.191 \\
\hline \multirow[t]{4}{*}{ Asian } & No. of loci with heterozygosity excess & & 10 & 9 & 7 & 6 & 5 & 5 \\
\hline & Wilcoxon test & $P$ value (one tail for heterozygosity deficiency) & 0.997 & 70.773 & 0.554 & 0.294 & 0.122 & 0.073 \\
\hline & & $P$ value (one tail for heterozygosity excess) & 0.004 & 0.249 & 0.946 & 0.729 & 0.892 & 0.936 \\
\hline & & $P$ value (two tails) & 0.009 & 0.497 & 0.946 & 0.588 & 0.244 & 0.146 \\
\hline
\end{tabular}

IAM, infinite alleles model; TPM, two-phase model (the number refers to the proportion of stepwise mutations); SMM, stepwise-mutation model. Significant $P$ values are highlighted in bold.

into context by testing whether low AFLP diversity is a feature of pinnipeds in general by exploiting a data set comprising five samples each of 14 different pinniped species genotyped at eight AFLP loci and by collating data from microsatellite primer notes and papers containing mtDNA data (Table 4). Figure 5 shows that the Steller's sea lion has low diversity relative to most of the other pinniped species at all three markers. Moreover, a strong positive correlation was found between current population size and the proportion of polymorphic AFLP loci $\left(r^{2}=0.49\right.$, $n=14, P=0.006$ ), suggesting that the low diversity at AFLP markers in this species may be a consequence of historically low population sizes. A similar but weaker pattern was obtained for mitochondrial DNA $\left(r^{2}=0.29\right.$, $n=19, P=0.017)$, but not for microsatellites $\left(r^{2}=0.14\right.$, $n=12, P=0.231)$. As with the population data, we also conducted tests using phylogenetic correction. For the phylogeny, we exploited the tree of Higdon et al. (2007), using the corrected divergence dates to produced branch lengths. When these trends were analysed using the program Continuous to correct for phylogenetic non-independence, the correlation between current population size and marker diversity was positive for all three markers and highly significant for AFLPs $(P<0.0001)$ but not for microsatellites $(P=0.67)$ or $\operatorname{mtDNA}(P=0.43)$.

\section{Discussion}

Herein, we report a study using three different commonly used genetic markers, microsatellites, AFLPs and mitochondrial DNA to assess levels of genetic diversity and population structure in the Steller's sea lion, and then to place this species in the wider context of pinnipeds in general. We find a significant pattern of isolation by distance and some evidence of a correlation between population size and genetic diversity. However, these patterns appear largely driven by differences among three different stocks with contrasting histories. Controlling for stock structure either by fitting stock as an extra predictor variable, or by implementing phylogenetic correction largely eliminates any population-specific effects. Among the pinnipeds, the Steller's sea lion seems to carry unexpectedly low levels of diversity, a pattern that is best reflected in AFLP markers which show the strongest correlation between diversity and current population size of the three markers we examined.

\section{Expectations from different markers}

Different markers are expected to reveal different aspects of a population's history, depending on their mode of inheritance and mutation rate. Thus, mitochondrial DNA will reveal patterns of maternally directed site fidelity while microsatellites, with their high mutation rates, will tend to recover high levels of variability following a population bottleneck faster than less mutable AFLP markers. Pinnipeds exhibit rather puzzling patterns of diversity that may be elucidated by the use of multiple marker types. Thus, elephant seals have extremely low diversity and were severely bottlenecked, but various fur seals were hunted just as hard and for longer yet carry the highest levels of microsatellite diversity seen among pinnipeds. Within a species, the Steller's sea lion has a broad geographical distribution and in parts of its range, populations are declining while elsewhere there appears to be expansion. These contrasting demographies may be 
(a) AFLPs $\left(r^{2}=0.49\right)$

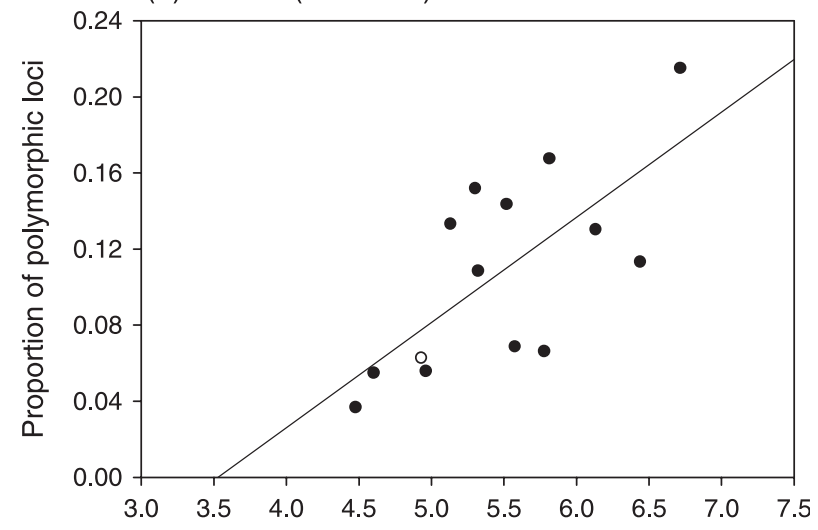

(b) Microsatellites $\left(r^{2}=0.14\right)$

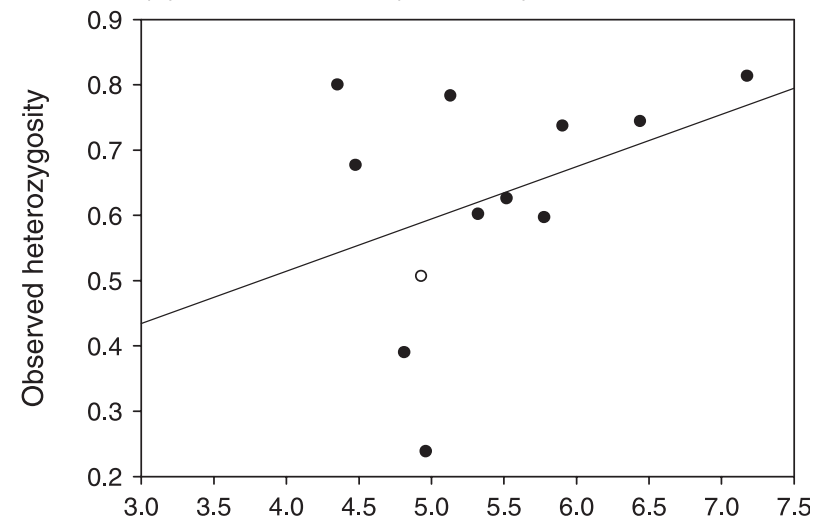

(c) $\mathrm{mtDNA}\left(r^{2}=0.29\right)$

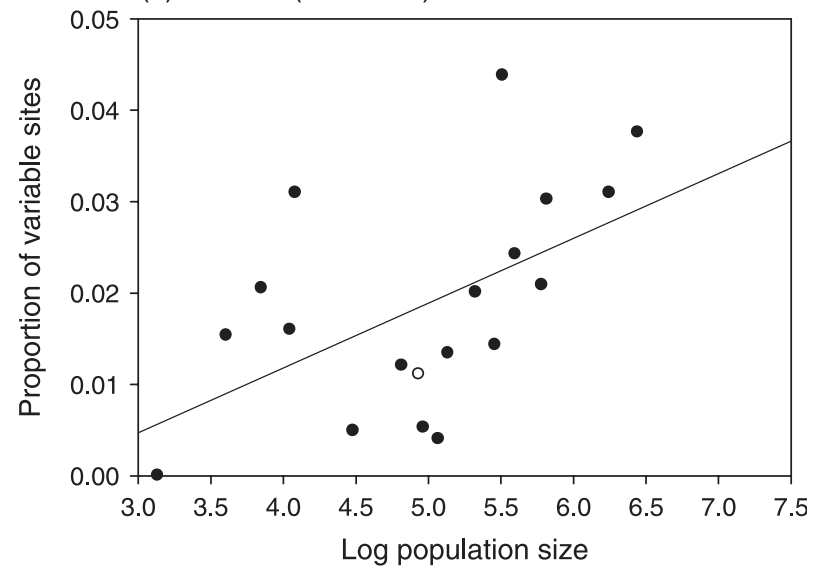

Fig. 5 Relationships between current estimated population size and genetic diversity at (a) AFLPs (b) microsatellites and (c) mtDNA across a range of pinniped species. White points indicate the Steller's sea lion. See Table 4 for details of sample sizes and literature references.

associated with the descendents of glacial refugia, which could inturn be reflected in distinct mitochondrial lineages. Finally, if widely reported trends linking microsatellite heterozygosity to individual fitness reflect a more general tendency for greater genetic diversity to improve a population's health, we might expect that the contrasting population trends seen among modern populations of Steller's sea lions will correspond to each population's heterozygosity.

\section{Genetic structure and links between diversity and population decline}

A pattern of isolation by distance is likely to arise under a wide range of circumstances, even in potentially highly mobile aquatic species such as pinnipeds (e.g. Allen et al. 1995; Goodman 1998; Campbell et al. 2007). For example, in the grey seal, many adults show high levels of breeding site fidelity and dispersal occurs mainly to available neighbouring sites when an individual's natal colony has reached carrying capacity (Gaggiotti et al. 2002). One might expect the Steller's sea lion to be no exception, distributed as it is over a vast geographical range in a series of breeding rookeries along the Aleutian chain and beyond, and this is what a naïve analysis reveals. However, previous studies have suggested the existence of at least two and possibly three different stocks, possibly reflecting the existence of historical ice age refugia (Bickham et al. 1996; Baker et al. 2005; Harlin-Cognato et al. 2005). Indeed, more recent morphological analysis has led to the suggestion that the eastern and western stock might even be considered subspecies (Phillips et al. in press). Once this structure has been corrected for by fitting stock as an extra parameter, the pattern of isolation by distance becomes non-significant, suggesting that the main driver of the apparent isolationby-distance pattern that we observe is the presence of rather dissimilar stocks. Use of Jost's $D$ instead of $F_{\mathrm{ST}}$, in theory allowing for the reduced resolution of $F_{\mathrm{ST}}$ in highly polymorphic systems, if anything only weakened any pattern of isolation by distance.

The presence of different genetically distinct stocks is problematic for most of the genetic analyses one might wish to conduct. This is because the shared ancestry within a stock creates some degree of statistical non-independence. To take an extreme example, if 10 populations were sampled from each of two stocks, one with high diversity and one with low diversity, any regression of diversity on a trait linked to stock identity, such as recent demography or geographical location, would tend to be highly significant (20 data points and a clear trend), when in fact only two fully independent observations exist. Our data feature the same problem, with two main stocks, east and west, but separate demographic trends for each of many subpopulations (i.e. breeding colonies). When we ignore stock structure, we find interesting patterns, but when stock structure is properly controlled, either by fitting stock as a predictor variable or by using phylogenetic correction, most of these correlations are eliminated. 
Our results using the program Continuous (Pagel 1997) also point to the need to assess critically whether the input phylogeny is valid. We obtained sharply contrasting results depending on the phylogeny we used. Based on data from all three markers pooled and normalized to ensure equal contribution from each, we obtained evidence of several perhaps suspiciously strong trends. However, when we used either a non-genetic tree based on geographical distances or the phylogeny that we believe most accurately reflects the likely true relationships among rookeries, these trends appear no longer significant. As yet, it is unclear which result is correct, although we prefer to be conservative and assume that the agreement between two contrasting but likely reliable trees provides the stronger evidence. Conversely, the fact that the combined marker phylogeny reveals trends not supported by two other trees suggests that while the combined tree maximizes the genetic information contributing to each genetic distance, tension between the different markers probably undermines the tree's reliability. Having said this, we feel this is an area where further work would be beneficial.

The general failure to uncover clear relationships between levels of genetic diversity and rookery size or population trend is perhaps not surprising. On the one hand, the levels of diversity that we find in this species appear rather low compared with other pinnipeds, arguably making it more difficult to resolve changes in diversity that might be linked to demography. At the same time, the main disjuncture within the metapopulation is between the Asian/ Western and the Eastern stocks, which are possibly even two subspecies (Phillips et al. in press), implying that within stocks there is appreciable gene flow among the different breeding colonies. Such gene flow will tend to mask or eliminate any possible differences in diversity that might otherwise result from the declines and expansions that have been documented over the last few decades. Moreover, the timescale of change is rather brief relative to the rate at which diversity is either lost or may accumulate, being of the order of only a few generations. Thus, when Bickham et al. (1998) used mtDNA to look for a loss in diversity between 1976 and 1978 and the 1990s in populations of the Central Gulf of Alaska, no significant differences were found, suggesting that reductions in population size over this period probably had a negligible effect on genetic diversity at this marker. However, the sample size used was small, including only 36 samples from the 1970s.

\section{Levels of genetic diversity in the Steller's sea lion}

In terms of AFLP diversity in particular, the Steller's sea lion seems to carry very low diversity. To place this observation in a broader context, we first attempted to compare our value with those reported for a range of vertebrates by Milot et al. (2007). However, interspecific comparisons of AFLP diversity are not straightforward. First, relatively few studies give the proportion of the total number of AFLP loci amplified that are polymorphic. Second, biases may arise from the use of different restriction enzymes (TaqI/EcoRI produces more polymorphic banding patterns in mammals, Ajmone-Marsan et al. 1997) or selective primers (those containing a CG motif at their $3^{\prime}$ end tend to amplify a higher proportion of polymorphic fragments, Bensch \& Akesson 2005; Milot et al. 2007). Third, some studies sample over wider geographical ranges than others, potentially capturing greater genetic diversity, and sample sizes also vary. Inter-observer variation may also be important, although Bonin et al. (2004) showed that even with only very limited overlap in the specific bands scored by different observers, the underlying phylogenetic signal remains much the same. However, Milot's use of $P_{5 \%}$ at least partly addresses these issues. For our data set, $P_{5 \%}$ is $5.9 \%$, which is low and comparable with the lowest values reported by Milot, those for the wandering (5.1\%) and Amsterdam (2.1\%) albatrosses which have undergone severe population bottlenecks. However, our measure of AFLP diversity may underestimate the true level of genetic diversity because we excluded 18 polymorphic loci that could not be scored reliably across all of the samples and which, if included, would raise our value to $21.5 \%$. This represents another potential problem in comparing values of diversity from different studies. Nonetheless, an allozyme study of the Steller's sea lion showed an almost complete lack of genetic variability (Lidicker et al. 1981). Since protein electrophoretic studies largely utilize relatively conservative nuclear housekeeping genes, they are more likely to produce results comparable to an AFLP analysis than nuclear microsatellites or mtDNA.

An interesting observation is the contrasting pattern of diversity between the two main stocks for nuclear and mitochondrial markers, the eastern stock carrying the greatest mtDNA diversity but the least nuclear diversity. Several hypotheses can be advanced for why this might be so. First, an appreciable component of the modern patterns will relate to what happened during and immediately after the last ice age. If the eastern stock lies closest to whatever refugia existed, the general tendency for pinnipeds to exhibit maternally directed site fidelity might have caused the western stock to have been founded by only a subset of mitochondrial lineages, despite receiving most of the nuclear diversity due to higher levels of male-mediated gene flow. A more general version of this concept would be to state that while nuclear diversity tends to reflect total population size within a stock, mitochondrial diversity may instead be linked to the number and stability of breeding colonies. Consequently, any demographic changes that reduce population size but not colony number will tend to erode nuclear more than mitochondrial variability, while 
local events that eliminate some colonies while allowing others to expand may have the converse effect. One further possibility that should not be discounted, particularly in a diving mammal where energy management is paramount, is that the mitochondrial genome could have at some point come under natural selection. Finally, our results are by no means unprecedented. For example, contrasting patterns of diversity were also found using AFLPs and mtDNA in the sonoma tree vole, with no population structure revealed by the former, but two distinct lineages uncovered using the latter (Blois \& Arbogast 2006). Here, genetic diversity was much higher for the mtDNA, re-emphasizing the benefit of using multiple markers to guard against any one yielding an unexpected/misleading pattern.

Ours is one of rather few studies that have examined patterns of genetic diversity across the entire range of a widely distributed species. It is generally recognized that higher levels of genetic diversity usually occur towards the centre of a species' range (e.g. Arnaud-Haond et al. 2006 and Schwartz et al. 2003), a pattern also seen in our data. The reasons for such a pattern are multiple. Ficetola et al. (2007) found that distance from glacial refugia and geographical isolation together explain over $90 \%$ of variation in microsatellite diversity in the frog Rana latastei in northern Italy, suggesting a major impact of sequential bottlenecks and/or founder events. Similar patterns are seen even among modern humans, reflecting loss of diversity as we moved out of Africa to colonize the world (Manica et al. 2005; Prugnolle et al. 2005). Interestingly, song sparrows distributed along the Aleutian chain and hence overlapping with the Steller's sea lion distribution also reveal a stepwise loss of microsatellites diversity, apparently due to founder events as the species moved from island to island (Pruett \& Winkler 2005).

Steller's sea lions appear to have unexpectedly low levels of genetic diversity, and one plausible explanation is a population bottleneck. However, applying the program Bottleneck, we failed to find any evidence of a recent severe reduction in population size. This largely supports other studies where although some species that have experienced a documented bottleneck such as the northern elephant seal have low diversity (Hoelzel et al. 1993), other species that were hunted to a similar or greater extent, such as many species of fur seal, currently have the highest levels of diversity seen among pinnipeds (e.g. Hoffman et al. 2003) and seem unaffected by sealing (e.g. Matthee et al. 2006). Indeed, one of the only species where a recent anthropogenic decline resulted in a detectable loss of diversity, verified by analysis of both pre- and postbottleneck samples, is the Mauritius kestrel, and this species declined to a single pair. Consequently, it seems likely that the patterns of diversity seen in modern populations will be dominated by longer-term demographic trends and have little to do with modern trends.

\section{Interspecific comparisons}

Even though short-term population trends appear to impact little on genetic diversity, the same may not be true of longer-term trends. Consequently, we examined a broad range of pinniped species to test whether current population size predicts diversity across the pinnipeds. Perhaps surprisingly, we find that while mtDNA and microsatellite diversity do not correlate significantly with population size after phylogenetic correction, AFLP markers do. The reason for the stronger relationship with AFLP markers is unclear but may relate to the relative rates of evolution of the three markers. Many of the largest changes in numbers have occurred recently and have been quite dramatic, with species of elephant seal, fur seal and sea lion having been exploited to near extinction and then rebounding. There are good reasons for believing that even these extreme histories will have reduced levels of diversity rather little, but any effects that are visible, both in terms of loss and regain of diversity will be most apparent in the fastest evolving markers which exhibit highest diversity, that is, mtDNA and microsatellites. Such markers are therefore more likely to be out of mutation-drift equilibrium, perhaps to some degree scrambling the relationship between diversity and current size. It would be interesting for future studies to ask whether stronger correlations could be obtained by using sighting data to reconstruct likely population histories for each species and then to allow for these in the estimation of current size. The strong result obtained for AFLP markers is also surprising because our sample sizes were small, at only five individuals per species. In terms only of assessing variability, the few individuals are in part compensated for by the scoring of large numbers of loci, although larger sample sizes would likely refine our estimates and, if anything, strengthen the AFLP result further. A bigger issue is likely to be whether five individuals can really represent a species across its entire range and possible population subdivisions. Our results surprisingly suggest it can, both from the strength of the regression of diversity on population size, and from the lack of structure seen within the Steller's sea lion. Clearly, this is an area where further study is warranted.

Comparing microsatellite and AFLP markers, we find a much stronger relationship with modern population size for the AFLPs. This is unexpected because many pinniped populations have in recent times experienced dramatic fluctuations due to hunting and habitat loss, and it seems logical that the faster evolving microsatellites would better track these changes. One possible explanation is that posthunting modern population sizes may have in many cases re-attained carrying capacity and hence approximate historical levels (e.g. Hodgson et al. 1998). If so, the slowly evolving AFLP markers may, through lack of response to rapid demographic change, exhibit a stronger correlation 
than microsatellites, which suffered a larger displacement from equilibrium and are still catching up. An alternative explanation is suggested by a recent observation that, across diverse human populations, microsatellite length is strongly predicted by heterozygosity (Amos et al. 2008). Interpreted as support for a model in which heterozygote genotypes are more mutable than equivalent homozygotes, this study suggests that for microsatellites at least, a simple relationship between heterozygosity and population size may not exist. Such a model might also help to explain why otariids have high microsatellite diversity because in this group hybridization between sister species is not unusual. Under heterozygote instability, the large increase in heterozygosity caused by hybridization would feed back to increase microsatellite mutation rate and hence diversity.

\section{Conclusion}

Genetic diversity is widely accepted as an important component of fitness and rare alleles can easily be lost following population decline. We find that the Steller's sea lion has unusually low diversity even compared with related species, with potential management implications. However, despite rapid declines in population size, particularly in rookeries of the western stock, we failed to find significant trends between demography and genetic diversity. This does not mean that such trends are absent, but detection will require larger sample sizes collected over a longer time period. In the meantime, the best way to prevent further erosion of variability is probably through active measures of intervention designed to prevent disappearance of key rookeries such as in the western Aleutian Islands where populations seem to be highly vulnerable.

\section{Acknowledgements}

We wish to thank the many people involved in collecting the tissues used in this study and in provision of the long-term data set, especially L. Rea, D. Calkins, L. Fritz, K. Pitcher, V. Burkanov, E. Mamaev, N. Pavlov, V. Vertjankin, and S. Zadal'sky. All animals were humanely treated according to ASM guidelines (American Society of Mammalogists 1998) and specimens were collected under Marine Mammal Protection Act permits 782-1532-02 issued to the National Marine Mammal Laboratory, and 358-1564 issued to the Alaska Department of Fish and Game. Funding for laboratory work and data analysis was provided by National Marine Fisheries Service and the National Marine Mammal Laboratory. Funding for field work was provided by NMFS, Alaska Department of Fish and Game, and the Alaska Sea Life Center. J.H. is currently supported by a Natural Environment Research Council (NERC) British Antarctic Survey (BAS) Strategic Alliance Fellowship.

\section{References}

Acevedo-Whitehouse K, Gulland F, Grieg D, Amos W (2003) Inbreeding: disease susceptibility in California sea lions. Nature, 422, 35.
Ajmone-Marsan J, Valentini A, Cassandro M, Vecchiotti-Antaldi G, Bertoni G, Kuiper M (1997) AFLP $_{\mathrm{TM}}$ markers for DNA fingerprinting in cattle. Animal Genetics, 28, 418-426.

Allen PJ, Amos W, Pomeroy PP, Twiss SD (1995) Microsatellite variation in grey seals (Halichoerus grypus) shows evidence of genetic differentiation between two British breeding colonies. Molecular Ecology, 4, 653-662.

Amos W, Flint J, Xu X (2008) Heterozygosity increases microsatellite mutation rate, linking it to demographic history. BMC Genetics, 9,72 .

Andersen LW, Born EW, Gjertz I, Wiig Ø, Holm LE, Bendixen C (1998) Population structure and gene flow of the Atlantic walrus (Odobenus rosmarus rosmarus) in the eastern Atlantic Arctic based on mitochondrial DNA and microsatellite variation. Molecular Ecology, 7, 1323-1336.

Andersen LW, Fog K, Damgaard C (2004) Habitat fragmentation causes bottlenecks and inbreeding in the European tree frog (Hyla arborea). Proceedings of the Royal Society B: Biological Sciences, 271, 1293-1302.

Arnaud-Haond S, Teixeira S, Massa S et al. (2006) Genetic structure at range-edge: low diversity and high inbreeding in SE Asia mangrove (Avicennia marina) populations. Molecular Ecology, 15, 3515-3525.

Atkinson S, DeMaster DP, Calkins DG (2008) Anthropogenic causes of the Steller sea lion decline and their threat to recovery. Mammal Review, 38, 1-18.

Baker AR, Loughlin TR, Burkanov V et al. (2005) Variation of mitochondrial control region sequences of Steller sea lions: the three-stock hypothesis. Journal of Mammalogy, 86, 1075-1084.

Ballard JWO, Whitlock MC (2004) The incomplete natural history of mitochondria. Molecular Ecology, 13, 729-744.

Bensch S, Akesson M (2005) Ten years of AFLP in ecology and evolution: why so few animals? Molecular Ecology, 14, 2899-2914.

Bickham JW, Patton JC, Loughlin TR (1996) High variability for control-region sequences in a marine mammal: implications for conservation and biogeography of Steller sea lions (Eumetopias jubatus). Journal of Mammalogy, 77, 95-108.

Bickham JW, Loughlin T, Calkins DG, Wickliffe JK, Patton J (1998) Genetic variability and population decline in Steller sea lions from the Gulf of Alaska. Journal of Mammalogy, 79, 1390-1395.

Blois JL, Arbogast BS (2006) Conservation genetics of the sonoma tree vole (Arborimus pomo) based on mitochondrial and amplified fragment length polymorphism markers. Journal of Mammalogy, 87, 950-960.

Bonin A, Bellemain E, Bronken Eidesen P, Pompanon F, Brochmann C, Taberlet $\mathrm{P}$ (2004) How to track and assess genotyping errors in population genetic studies. Molecular Ecology, 13, 32613273.

Buchanan FC, Maiers LD, Thue TD, DeMarch BGE, Stewart REA (1998) Microsatellites from the Atlantic walrus Odobenus rosmarus rosmarus. Molecular Ecology, 7, 1083-1085.

Campbell RA (2003) Demography and Genetic Population Structure of the Australian Sea Lion (Neophoca cinerea). Department of Zoology, University of Western Australia, Perth, Australia.

Campbell RA, Gales NJ, Lento GM, Baker CS (2007) Islands in the sea: extreme female natal site fidelity in the Australian sea lion, Neophoca cinerea. Biology Letters, 4, 139-142.

Cena C, Morgan GE, Malette MD, Heath DD (2006) Inbreeding, outbreeding and environmental effects on genetic diversity in 46 walleye (Sander vitreus) populations. Molecular Ecology, 15, 303-320. 
Coltman DW, Bowen WD, Wright JM (1996) PCR primers for harbour seal (Phoca vitulina concolour) microsatellites amplify polymorphic loci in other pinniped species. Molecular Ecology, 5, 161-163.

Coltman DW, Pilkington JG, Smith JA, Pemberton JM (1999) Parasite-mediated selection against inbred Soay sheep in a free-living, island population. Evolution, 53, 1259-1267.

Coltman DW, Stenson G, Hammill MO, Haug T, Davis CS, Fulton TL (2007) Panmictic population structure in the hooded seal (Cystophora cristata). Molecular Ecology, 16, 16391648.

Crawley MJ (2002) Statistical Computing: An Introduction to Data Analysis using S-plus. John Wiley and Sons Ltd, Chichester, UK.

Dasmahapatra KK, Hoffman JI, Amos W (online early) Pinniped phylogenetic relationships inferred using AFLP markers. Heredity. doi:10.1038/hdy.2009.25.

Davis CS, Gelatt TS, Siniff D, Strobeck C (2002) Dinucleotide microsatellite markers from the Antarctic seals and their use in other pinnipeds. Molecular Ecology Notes, 2, 203-208.

Ellegren $H$ (2000) Microsatellite mutations in the germline: implications for evolutionary inference. Trends in Genetics, 16, 551-558.

Evanno G, Regnaut S, Goudet J (2005) Detecting the number of clusters of individuals using the software Structure: a simulation study. Molecular Ecology, 14, 2611-2620.

Falush D, Stephens M, Pritchard JM (2007) Inference of population structure using multilocus genotype data: dominant markers and null alleles. Molecular Ecology Notes, 7, 574-578.

Felsenstein J (1993) PHYLIP (Phylogeny Inference Package) version 3.5c. Distributed by the author. Department of Genetics, University of Washington, Seattle, Washington.

Ficetola GF, Garner TWJ, De Bernadi F (2007) Genetic diversity, but not hatching success, is jointly affected by postglacial colonization and isolation in the threatened frog, Rana latastei. Molecular Ecology, 16, 1787-1797.

Gaggiotti OE, Jones F, Lee WM, Amos W, Harwood J, Nichols RA (2002) Patterns of colonization in a metapopulation of grey seals. Nature, 416, 424-427.

Goldsworthy S, Francis J, Boness D, Fleischer R (2000) Variation in the mitochondrial control region in the Juan Fernandez Fur Seal (Arctocephalus philippi). Journal of Heredity, 91, 371-377.

Goodman SJ (1997) Dinucleotide repeat polymorphisms at seven anonymous microsatellite loci cloned from the European Harbour Seal (Phoca vitulina vitulina). Animal Genetics, 28, 310311.

Goodman SJ (1998) Patterns of extensive genetic differentiation and variation among European harbor seals (Phoca vitulina vitulina) revealed using microsatellite DNA polymorphisms. Molecular Biology and Evolution, 15, 104-118.

Goudet J (1995) FSTAT (version 1.2): a computer program to calculate F-statistics. Journal of Heredity, 86, 485-486.

Harlin-Cognato A, Bickham AW, Loughlin TR, Honeycutt RL (2005) Glacial refugia and the phylogeography of Steller's sea lion (Eumetopias jubatus) in the North Pacific. Journal of Evolutionary Biology, 19, 955-969.

Hernandez-Velazquez FD, Galindo-Sanchez CE, Taylor MI et al. (2005) New polymorphic microsatellite markers for California sea lions (Zalophus californianus). Molecular Ecology Notes, 5, 140142.

Higdon JW, Bininda-Edmonds ORP, Beck RMD, Ferguson SH (2007) Phylogeny and divergence of the pinnipeds (Carnivora:
Mammalis) assessed using a multigene dataset. BMC Evolutionary Biology, 7, 216.

Hodgson DA, Johnston NM, Caulkett AP, Jones VJ (1998) Palaeolimnology of Antarctic fur seal Arctocephalus gazella populations and implications for Antarctic management. Biological Conservation, 83, 145-154.

Hoelzel AR, Halley J, O'Brien SJ et al. (1993) Elephant seal genetic variation and the use of simulation models to investigate historical population bottlenecks. Journal of Heredity, 84, 443449.

Hoelzel AR, LeBoeuf BJ, Reiter J, Campagna C (1999) Alpha-male paternity in elephant seals. Behavioral Ecology Sociobiology, 46, 298-306.

Hoffman JI (online first) A panel of new microsatellite loci for genetic studies of Antarctic fur seals and other otariids. Conservation Genetics. 10.1007/s10592-008-9669-z.

Hoffman JI, Amos W (2005) Microsatellite genotyping errors: detection approaches, common sources and consequences for paternal exclusion. Molecular Ecology, 14, 599-612.

Hoffman JI, Boyd ILB, Amos W (2003) Male reproductive strategy and the importance of maternal status in the Antarctic fur seal Arctocephalus gazella. Evolution, 57, 1917-1930.

Hoffman JI, Matson C, Amos W, Loughlin TR, Bickham JW (2006) Deep genetic subdivision within a continuously distributed and highly vagile marine mammal, the Steller's sea lion Eumetopias jubatus. Molecular Ecology, 15, 2821-2832.

Hoffman JI, Steinfartz S, Wolf JBW (2007) Ten novel dinucleotide microsatellite loci cloned from the Galápagos sea lion (Zalophus californianus wollebaeki) are polymorphic in other pinniped species. Molecular Ecology Notes, 7, 103-105.

Hoffman JI, Dasmahapatra KK, Nichols HJ (2008) Ten novel polymorphic dinucleotide microsatellite loci cloned from the Antarctic fur seal Arctocephalus gazella. Molecular Ecology Resources, 8, 459-461.

Huebinger RM, Louis Jr EE, Gelatt T, Rea LD, Bickham JW (2007) Characterization of eight microsatellite loci in Steller sea lions (Eumetopias jubatus). Molecular Ecology Notes, 7, 1097-1099.

Luikart G, Cornuet JM (1998) Emprical evalution of a test for identifying recently bottlenecked populations from allele frequency data. Conservation Biology, 12, 228-237.

Jones CJ, Edwards KJ, Castaglione S et al. (1997) Reproducibility testing of RAPD, AFLP and SSR markers in plants by a network of European laboratories. Molecular Breeding, 3, 381-390.

Jost L (2008) GST and its relatives do not measure differentiation. Molecular Ecology, 17, 4015-4026.

Kenyon KW, Rice DW (1961) Abundance and distribution of the Steller sea lion. Journal of Mammalogy, 42, 223-234.

Knaepkens G, Knapen D, Bervoets L, Hanfling B, Verheyen E, Eens M (2002) Genetic diversity and condition factor: a significant relationship in Flemish but not in German populations of the European bullhead (Cottus gobio L.). Heredity, $89,280-287$.

Kretzmann MB, Gilmartin WG, Meyer A et al. (1997) Low genetic variability in the Hawaiian monk seal. Conservation Biology, 11, 482-490.

Lidicker WZJ, Sage RD, Calkins DG (1981) Biochemical variation in northern sea lions from Alaska. In: Mammalian Population Genetics (eds Smith MH, Joule J), pp. 231-244. University of Georgia Press, Athens, Georgia. 
Liedloff AC (1999) Mantel Nonparametric Test Calculator, Version 2.0. School of Natural Resource Sciences, Queensland University of Technology, Australia.

Loughlin TR, York AE (2000) An accounting of the sources of Steller sea lion, Eumetopias jubatus, mortality. Marine Fisheries Review, 62, 40-45.

Loughlin TR, Perlov AS, Vladimirov VA (1992) Range-wide survey and estimation of total number of Steller sea lions in 1989. Marine Mammal Science, 8, 220-239.

Maldonado JE, Davila FO, Stewart BS, Geffen E, Wayne RK (1995) Intraspecific genetic differentiation in California sea lions (Zalophus californianus) from Southern California and the Gulf of California. Marine Mammal Science, 11, 46-58.

Manica A, Prugnolle F, Balloux F (2005) Geography is a better determinant of human genetic differentiation than ethnicity. Human Genetics, 118, 366-371.

Matthee CA, Fourie F, Oosthuizen WH, Meyer MA, Tolley KA (2006) Mitochondrial DNA sequence data of the Cape fur seal (Arctocephalus pusillus pusillus) suggest that population numbers maybe affected by climatic shifts. Marine Biology, 148, 899-905.

Meudt HM, Clarke AC (2007) Almost forgotten or latest practice? AFLP applications, analyses and advances. Trends in Plant Science, 12, 106-108.

Miller-Butterworth CM, Jacobs DS, Harley EH (2003) Strong population substructure is correlated with morphology and ecology in a migratory bat. Nature, 424, 187-191.

MilotE, Weimerskirch H, DuchesneP, Bernatchez L (2007) Surviving with low genetic diversity: the case of albatrosses. Proceedings of the Royal Society B: Biological Sciences, 274,779-787.

Mizuno AW, Onuma M, Takahashi M, Ohtaishi N (2003) Population genetic structure of the spotted seal Phoca largha along the coast of Hokkaido, based on mitochondrial DNA sequences. Zoological Science, 20, 783-788.

Nei M (1987) Molecular Evolutionary Genetics. Columbia University Press, New York.

O'Corry-Crowe G, Taylor BL, Gelatt T et al. (2007) Demographic independence along ecosystem boundaries in Steller sea lions revealed by mtDNA analysis: implications for management of an endangered species. Canadian Journal of Zoology, 84, 17961809.

Pagel M (1997) Inferring evolutionary processes from phylogenies. Zoologica Scripta (Journal of the Royal Swedish Academy) 25th Anniversary Special Issue on Phylogenetics and Systematics, 26, 331348.

Pagel M (1999) The maximum likelihood approach to reconstructing ancestral character states of discrete characters on phylogenies. Systematic Biology, 48, 612-622.

Philips CD, Bickham JW, Patton JC, Gelatt TS (2009) Systematics of Steller Sea Lions (Eumetopias jubatus): Subspecies Recognition Based on Concordance of Genetics and Morphometrics. Occasional Papers, Museum of Texas Tech University, 283, 1-15.

Piry S, Luikart G, Cornuet JM (1999) BOTTLENECK: a computer program for detecting recent reductions in the effective population size using allele frequency data. Journal of Heredity, 90, 502-503.

Pompanon F, Bonin A, Bellemain E, Taberlet P (2005) Genotyping errors: causes, consequences and solutions. Nature Reviews Genetics, 6, 847-859.

Pritchard JK, Stephens M, Donnelly P (2000) Inference of population structure using multilocus genotype data. Genetics, 155, 945-959.
Pruett CL, Winkler K (2005) Northwestern song sparrow populations show genetic effects of sequential colonization. Molecular Ecology, 14, 1421-1434.

Prugnolle F, Manica A, Balloux F (2005) Geography predicts neutral genetic diversity of human populations. Current Biology, 15, R159-R160.

$\mathrm{R}$ development Team (2005) R: A Language and Environment for Statistical Computing. R Foundation for Statistical Computing, Vienna, Austria.

Reed DH, Frankham R (2003) Correlation between fitness and genetic diversity. Conservation Biology, 17, 230-237.

Rojas J, Rojas R (1995) DnaSP, DNA sequence polymorphism: an interactive program for estimating population genetics parameters from DNA sequence data. Computer Applications in the Biosciences, 11, 621-625.

Rowe G, Beebee TJC, Burke T (1999) Microsatellite heterozygosity, fitness and demography in natterjack toads Bufo calamita. Animal Conservation, 2, 85-92.

Saccheri I, Kuussaari M, Kankare M, Vikman P, Fortelius W, Hanski I (1998) Inbreeding and extinction in a butterfly metapopulation. Nature, 392, 491-494.

Sambrook J, Fritsch EF, Maniatis T (1989) Molecular Cloning: A Laboratory Manual. Cold Spring Harbour Laboratory Press, New York.

Schlotterer C (2004) The evolution of molecular markers-just a matter of fashion? Nature Reviews Genetics, 5, 63-69.

Schneider S, Roessli D, Excoffier L (2000) Arlequin ver 2.000: A Software for Population Genetics Data Analysis. Genetics and Biometry Laboratory, Department of Anthropology and Ecology, University of Geneva, Geneva, Switzerland.

Schwartz MK, Mills LS, Ortega Y, Ruggiero LF, Allendorf FW (2003) Landscape location affects genetic variation of Canada lynx (Lynx Canadensis). Molecular Ecology, 12, 18071816.

Selkoe KA, Toonen RJ (2006) Microsatellites for ecologists: a practical guide to using and evaluating microsatellite markers. Ecology Letters, 9, 615-629.

Shikano T, Taniguchi N (2002) Heterosis for neonatal survival in the guppy. Journal of Fish Biology, 60, 715-725.

Stanley HF, Casey S, Carnahan JM, Goodman S, Harwood J, Wayne RK (1996) Worldwide patterns of mitochondrial DNA differentiation in the harbor seal (Phoca vitulina). Molecular Biology and Evolution, 13, 368-382.

Tamura K, Dudley J, Nei M, Kumar S (2007) Molecular evolutionary genetics analysis (MEGA) software, version 4.0. Molecular Biology and Evolution, 24, 1596-1599.

Valsecchi E, Amos W, Raga JA, Podesta M, Sherwin W (2004) The effects of inbreeding on mortality during a morbillivirus outbreak in the Mediterranean striped dolphin (Stenella coeruleoalba). Animal Conservation, 7, 139-146.

Vazquez-Dominguez E, Pinero D, Ceballos G (1999) Linking heterozygosity, demography, and fitness of tropical populations of Liomys pictus. Journal of Mammalogy, 80, 810-822.

Vekemans X (2002) AFLP-SURV version 1.0. Distributed by the author. Laboratoire de Génétique et Ecologie Végétale, Université Libre de Bruxelles, Belgium.

Vos P, Hogers R, Bleker M et al. (1995) AFLP: a new technique for DNA fingerprinting. Nucleic Acids Research, 23, 4407-4414. 
Waits L, Taberlet P, Swenson JE, Sandgren F, Franzen R (2000) Nuclear DNA microsatellite analysis of genetic diversity and gene flow in the Scandinavian brown bear (Ursus arctos). Molecular Ecology, 9, 421-431.

Weber DS, Stewart BS, Garza JC, Lehman N (2000) An empirical genetic assessment of the severity of the northern elephant seal population bottleneck. Current Biology, 10, 1287-1290.

Weber DS, Stewart BS, Lehman N (2004) Genetic consequences of a severe population bottleneck in the Guadalupe fur seal (Arctocephalus townsendi). Journal of Heredity, 95, 144-153.

Whiteman NK, Matson KD, Bollmer JL, Parker PG (2006) Disease ecology in the Galapagos hawk (Buteo galapagoensis): host diversity, parasite load and natural antibodies. Proceedings of the Royal Society B: Biological Sciences, 273, 797-804.

Wolf JBW, Tautz D, Caccone A, Steinfartz S (2005) Development of new microsatellite loci and evaluation of loci from other pinniped species for the Galapagos sea lion (Zalophus californianus wollebaeki). Conservation Genetics, 7, 103-105.

Wright S (1951) The genetical structure of populations. Annals of Eugenics, 15, 323-354.

Wynen LP, Goldsworthy SD, Guinet C et al. (2000) Postsealing genetic variation and population structure of two species of fur seal (Arctocephalus gazella and A. tropicalis). Molecular Ecology, 9, 299-314.

Zhang D-X, Hweitt GM (2003) Nuclear DNA analyses in genetic studies of populations: practice, problems and prospects. Molecular Ecology, 12, 563-584.
This paper is one in a series resulting from a long-term study (since 1992) on the population genetics and systematics of Steller's sea lions sponsored mainly by NMFS. Joe Hoffman specialises in the molecular ecology of natural vertebrate populations and is also interested in the population genetics of a variety of Antarctic marine organisms. Kanchon Dasmahapatra is a molecular ecologist conducting research in speciation, phylogenetics and conservation genetics. Bill Amos runs the Molecular Ecology group and has a long-standing interest in understanding the distribution of variability in natural populations. His favorite wine of the moment is Chateau Musar 1991, outstanding! Caleb Phillips is interested in molecular evolution and phylogeography. Tom and his research group are responsible for investigating various research questions pertaining to the declining populations of Stellar's sea lions contribute to a wide assortment of projects involving animal foraging behaviour, demographics, and abundance estimation to collectively address these questions and provide fisheries management direction. John Bickham's research interests focus on genetic mutations and how they are produced and transmitted in individuals, populations, species and the evolutionary processes that affect genetic change. His current research projects include population genetics of Stellar's sea lions and bowhead whales, biodiversity studies in bats and ecotoxicological studies in contaminated environments in Azerbaijan. 